\title{
Metabolic Syndrome Associated with Polycystic Ovary Syndrome in Some Nigerian Women
}

\section{Daniel Adewuni ${ }^{1,2}$, Titilola A. Samuel ${ }^{2,3}$, Bolanle Iranloye ${ }^{2,4}$, Olubunmi Magbagbeola $^{2,3}$ and Oluyemi Akinloye ${ }^{1,2^{*}}$}

${ }^{I}$ Department of Medical Laboratory Sciences, Faculty of Basic Medical Sciences, College of Medicine of the University of Lagos

${ }^{2}$ Centre for Genomics of Non-communicable and Personalized Healthcare, University of Lagos

${ }^{3}$ Department Department of Biochemistry, Faculty of Basic Medical Sciences, College of Medicine of the University of Lagos

${ }^{4}$ Department of Physiology, College of Medicine of the University of Lagos.

*Correspondence should be addressed to Oluyemi Akinloye: oakinloye@unilag.edu.ng

Received 27th December 2021; Revised 8th January 2022; Accepted 11th January 2022

(C) 2022 Adewuni et al. Licensee Pan African Journal of Life Sciences an official publication of Faculty of Basic Medical Sciences, Ladoke Akintola University of Technology, Ogbomoso. This is an Open Access article distributed under the terms of the Creative commons Attribution License (https://creativecommons.org/licenses/BY/4.0), which permits unrestricted use, distribution, and reproduction in any medium, provided the original work is properly cited.

\begin{abstract}
Background: Polycystic Ovary Syndrome (PCOS) is a group of symptoms associated with endocrine disorders in women of reproductive age. Women with this syndrome is at increased risk of metabolic syndrome. This study described the metabolic syndrome and its associated components among women with PCOS in Nigerian populace.
\end{abstract}

\begin{abstract}
Methods: A total of 90 participants (50 PCOS and 40 controls) were recruited for the study. The diagnosis of PCOS was established using the criteria defined by International PCOS guidelines 2018. Demographic, anthropometric, and clinicopathological data, including blood pressure, were obtained for each participant. Metabolic syndrome was diagnosed using the 2005 revised National Cholesterol Education Program Adult Treatment Panel-III (revised NCEP ATP_III) guidelines. Fasting blood glucose, insulin, total cholesterol, HDL, LDL, and triglycerides were evaluated with conventional spectrophotometric methods.
\end{abstract}

Results: The prevalence of metabolic syndrome in PCOS women was $24 \%$, with an odds ratio of 5.211, while the prevalence of $5.7 \%$ was observed in the control group. The prevalence of central obesity (waist circumference $>88 \mathrm{~cm}$ ), FBS $\geq 100$ $\mathrm{mg} / \mathrm{dl}, \mathrm{HDL}<50 \mathrm{mg} / \mathrm{dl}$, triglycerides $\geq 150 \mathrm{mg} / \mathrm{dl}$, and blood pressure $\geq 130 / 85 \mathrm{mmHg}$ in PCOS women was $60 \%, 22 \%, 54 \%$, $12 \%$, and $20 \%$, respectively. The most frequently observed individual components of metabolic syndrome were increased waist circumference and decreased HDL cholesterol.

Conclusion: Metabolic syndrome and its components, especially obesity, are a major risk factor of PCOS in our population. Routine screening and modulating individual contributors of metabolic syndrome may support PCOS management.

Keywords: Polycystic Ovarian Syndrome, Metabolic Syndrome, Risk Factors. 


\subsection{INTRODUCTION}

Polycystic Ovary Syndrome (PCOS) is a group of symptoms associated with endocrine disorders and has been described as the main endocrine disorder in women [1]. The global prevalence of PCOS has been reported to range from $6 \%$ to $10 \%$ [2]. There is a reported $5.6 \%$ prevalence rate in Chinese women and a $2.2 \%$ prevalence in Nigeria [3, 4]. Different diagnostic criteria are believed to have contributed to the variation in the prevalence of PCOS reported across various populations. The criteria for Diagnosing PCOS have been provided by four scientific bodies: the National Institutes of Health [5]; the European Society for Human Reproduction and Embryology/American Society for Reproductive Medicine [6]; the Androgen Excess and PCOS Society (AES) [7], and the International PCOS Guidelines [8]. The clinical manifestations of PCOS include hyperandrogenism, oligomenorrhea or amenorrhea, hirsutism, and chronic anovulation. The PCOS women are at increased risk of developing metabolic syndrome [9]. Metabolic syndrome (MS) is a cluster of clinical risk factors for the development of cardiovascular diseases (CVD) and diabetes, and these factors include abdominal obesity, dyslipidemia, glucose metabolic disorders, especially insulin resistance with or without glucose intolerance and elevated blood pressure [10,11]. Though different definitions of metabolic syndrome criteria exist, the concept of clustering of risks leading to diabetes and cardiovascular disease (CVD) is well accepted. Several expert groups: the World Health Organization [WHO], the American Association of Clin-ical Endocrinologists [AACE], International Diabetes Foundation (IDF), and National Cholesterol Education Program - Third Adult Treatment Panel (NCEP ATP III) have published diag--nostic criteria for the identification and clinical diagnosis of metabolic syndrome. These criteria have emerged based on each group's relative importance to certain risk factors associated with metabolic syndrome. A prevalence of $33.6 \%$ was reported in PCOS women in Brazil [12].

Similarly, a prevalence of $22.7 \%$ was reported in Iranian women with PCOS [13]. The metabolic syndrome (MS) and the polycystic ovary syndrome (PCOS) seem to be intertwined even though they are separate disorders. This relationship could be partly attributed to observed common features like insulin resistance, obesity, and risk of cardiovascular disease. Obesity has been reported to amplify hyperandrogenism in PCOS, resulting in increased total testosterone, free androgen index, and decreased sex hormone-binding globulin (SHBG) [14]. Also, the androgen excess observed in PCOS has been suggested to directly influence adipocyte function [15]. While the contribution of these individual parameters continues to attract interest in both MS and PCOS, the metabolic syndrome continues to drive the twin global epidemics of type 2 diabetes and cardiovascular disease. However, there is an overwhelming medical and economic imperative to identify the risk of developing metabolic syndrome in individuals with PCOS.

\subsection{METHODOLOGY}

A total of 90 participants (50 PCOS and 40 controls) were recruited for the study. PCOS diagnosis was established using the criteria as defined by International PCOS guidelines 2018, requiring the presence of any two of (1) Oligomenorrhea - and/or anovulation, (2) Clinical and/or biochemical signs of hyperandrogenism, and (3) Polycystic ovary morphology (presence of 12 or more follicles in each ovary, 2-9 $\mathrm{mm}$ in diameter and/or increased ovarian volume $>10 \mathrm{~mL}$ ). Apparently, healthy women with no PCOS were recruited as controls. Ethical approval was obtained from the institutional Health Research and Ethics Committee prior to the commencement of the study (CMUL/HREC/05/19/527).

General demographic and clinicopathological details were obtained from the participants. Anthropometric data such as height, weight, waist circumference, and hip circumference were measured, and the body mass index (BMI) was calculated as weight $(\mathrm{kg}) /$ height $^{\wedge} 2\left(\mathrm{~m}^{2}\right)$, while the weight hip ratio (WHR) was calculated as the measurements of the waistline/hipline ratio. Fasting blood glucose, total cholesterol, HDL, LDL, and triglycerides were analyzed by photometry method using Roche Cobas C111 clinical Chemistry analyzer. Insulin was assayed using electrochemiluminescence (ECL) technology (Roche Diagnostics, Switzerland).

Metabolic syndrome was assessed using the 2005 revised National Cholesterol Education Program Adult Treatment Panel-III (revised NCEP ATP_III) guidelines which recommended the presence of at least any three of the following: (1) abdominal obesity given as waist circumference [ $>88 \mathrm{~cm}$ ( $>35$ in)], (2) triglycerides $\geq 150$ $\mathrm{mg} / \mathrm{dL}$, (3) HDL cholesterol $<50 \mathrm{mg} / \mathrm{d}$, (4) systolic/ diastolic blood pressure $\geq 130 / 85 \mathrm{mmHg}$, and (5) fasting plasma glucose $\geq 100 \mathrm{mg} / \mathrm{dL}$ [16]. 


\subsection{Statistical Analysis}

Statistical data analysis was performed using IBM SPSS version 25 (IBM Illinois, USA). Data were analyzed using student's t-test, Mann-Whitney U, Chi-Square, and Logistic regression, where appropriate. A p-value $<0.05$ was considered statistically significant.

\subsection{RESULTS}

Table 1 shows the demographic and anthropometric characteristics of the PCOS and controls. The mean weight, BMI, waist circumference, and waist-hip ratio were higher in PCOS $(77.70 \pm 15.7,29.57 \pm 6.0,0.93 \pm 0.1$ and $0.87 \pm 0.1$, respectively) compared to the controls $(68.43 \pm 11.5,26.19 \pm 4.4,0.87 \pm 0.1$ and $0.83 \pm 0.1$, respectively) $\mathrm{p}<0.05$.

Table 1. Comparison of Demographic and Anthropometric Parameters in the Study Population

\begin{tabular}{|c|c|c|c|c|}
\hline Parameter & $\begin{array}{l}\text { PCOS } \\
\text { Mean } \pm \text { SD }\end{array}$ & $\begin{array}{l}\text { Control } \\
\text { Mean } \pm \text { SD }\end{array}$ & t-value & p-value \\
\hline Age (Years) & $29.44 \pm 5.0$ & $30.83 \pm 4.0$ & -1.367 & 0.175 \\
\hline $\begin{array}{l}\text { Age at menar- } \\
\text { che (Years) }\end{array}$ & $13.15 \pm 2.2$ & $14.13 \pm 2.3$ & -1.131 & 0.264 \\
\hline Weight (Kg) & $77.70 \pm 15.7$ & $68.43 \pm 11.5$ & 2.942 & $0.004 *$ \\
\hline Height (m) & $1.62 \pm 0.1$ & $1.72 \pm 0.6$ & -1.124 & 0.264 \\
\hline BMI $\left(\mathrm{Kg} / \mathrm{m}^{2}\right)$ & $29.57 \pm 6.0$ & $26.19 \pm 4.4$ & 2.810 & $0.006 *$ \\
\hline $\begin{array}{l}\text { Waist circum- } \\
\text { ference }(\mathrm{m})\end{array}$ & $0.93 \pm 0.1$ & $0.87 \pm 0.1$ & 2.666 & $0.026 *$ \\
\hline $\begin{array}{l}\text { Hip- } \\
\text { circumference } \\
\text { (m) }\end{array}$ & $1.07 \pm 0.1$ & $1.04 \pm 0.1$ & 1.369 & 0.175 \\
\hline $\begin{array}{l}\text { Waist hip } \\
\text { ratio }\end{array}$ & $0.87 \pm 0.1$ & $0.83 \pm 0.1$ & 2.304 & $0.024 *$ \\
\hline
\end{tabular}

*Difference is statistically significant, $\mathrm{p}<0.05$

Table 2. Comparison of Biochemical Data in Cases and Control Groups

\begin{tabular}{|c|c|c|c|c|}
\hline Parameter & $\begin{array}{l}\text { PCOS } \\
\text { Mean } \pm \text { SD }\end{array}$ & $\begin{array}{l}\text { Control } \\
\text { Mean } \\
\text { SD }\end{array}$ & t-value & $\begin{array}{l}\text { p- } \\
\text { value }\end{array}$ \\
\hline $\begin{array}{l}\text { Cholesterol (mg/ } \\
\text { dl) }\end{array}$ & $178.56 \pm 43.9$ & $\begin{array}{l}175.21 \pm 28 \\
.7\end{array}$ & 0.396 & 0.693 \\
\hline HDL (mg/dl) & $49.52 \pm 11.6$ & $\begin{array}{l}56.73 \pm 13 \\
3\end{array}$ & -2.653 & $0.010 *$ \\
\hline LDL (mg/dl) & $112.34 \pm 41.0$ & $\begin{array}{l}108.53 \pm 25 \\
.6\end{array}$ & 0.486 & 0.628 \\
\hline $\begin{array}{l}\text { Triglyceride } \\
\text { (mg/dl) }\end{array}$ & $95.02 \pm 39.2$ & $\begin{array}{l}78.02 \pm 35 \\
9\end{array}$ & 2.011 & $0.048 *$ \\
\hline \multirow[t]{2}{*}{ Glucose (mg/dl) } & $89.82 \pm 23.1$ & $\begin{array}{l}86.10 \pm 13 \\
3\end{array}$ & 0.856 & 0.394 \\
\hline & $\begin{array}{l}\text { Median (Q1- } \\
\text { Q3) }\end{array}$ & $\begin{array}{l}\text { Median } \\
\text { (Q1-Q3) }\end{array}$ & U-value & $\begin{array}{l}\text { p- } \\
\text { value }\end{array}$ \\
\hline Insulin (uU/ml) & $\begin{array}{l}13.59(9.4- \\
21.1)\end{array}$ & $\begin{array}{l}8.63(5.1- \\
30.3)\end{array}$ & -1.079 & 0.281 \\
\hline
\end{tabular}

*Difference is statistically significant, $\mathrm{p}<0.05$
Table 2 shows the biochemical analysis in the PCOS and controls; the mean HDL was lower in PCOS $(49.52 \pm 11.6)$ compared to the controls $(56.73 \pm 13.3)$ $\mathrm{p}<0.05$, and the mean triglycerides were higher in PCOS $(95.02 \pm 39.2)$ compared to the controls (78.02 \pm 35.9$)$ $\mathrm{p}<0.05$. Figure 1 shows the occurrence of metabolic syndrome in the PCOS and controls, indicating a prevalence of $24 \%$ and $5.7 \%$, respectively.

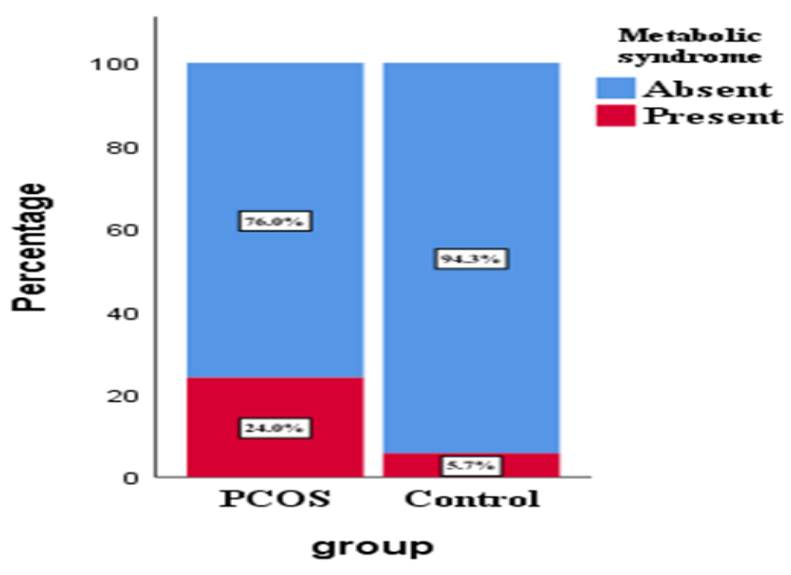

Figure 1. Prevalence of Metabolic Syndrome among PCOS and Control Group

*Difference is statistically significant, $\mathrm{p}<0.05$

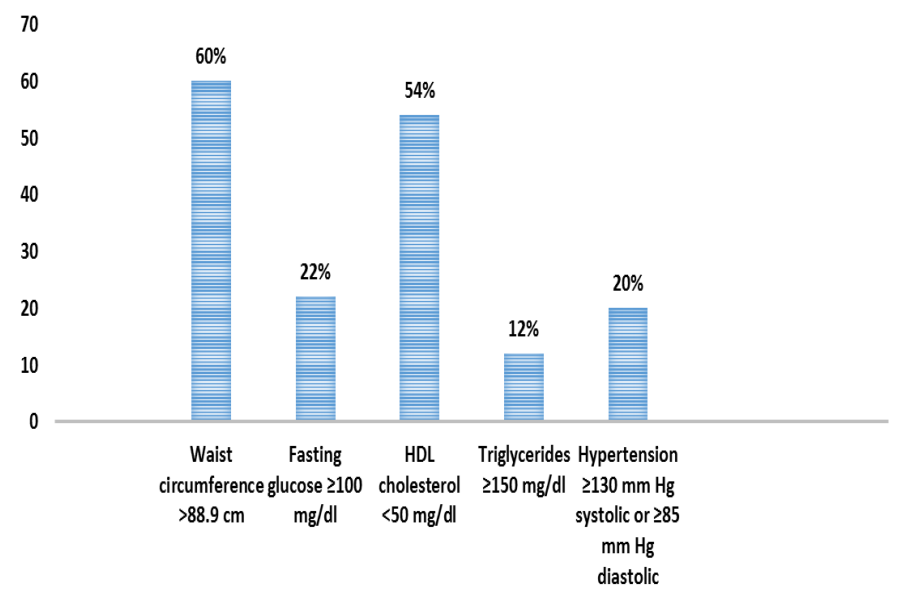

Figure 2. Occurrence of Individual Components of the Metabolic Syndrome in PCOS 
Figure 2 shows the distribution of different components of metabolic syndrome in the PCOS study population. The most common individual features of the metabolic syndrome were higher waist circumference and reduced HDL cholesterol (60\% and $54 \%$ of PCOS, respectively). The waist circumference exceeded $88.9 \mathrm{~cm}$ in $60 \%$, HDL cholesterol was less than $50 \mathrm{mg} / \mathrm{dl}$ in $54 \%$, triglycerides were $150 \mathrm{mg} / \mathrm{dl}$ or greater in $12 \%$. Blood pressure was $130 / 85 \mathrm{~mm} \mathrm{Hg}$ or greater in $20 \%$, and fasting glucose

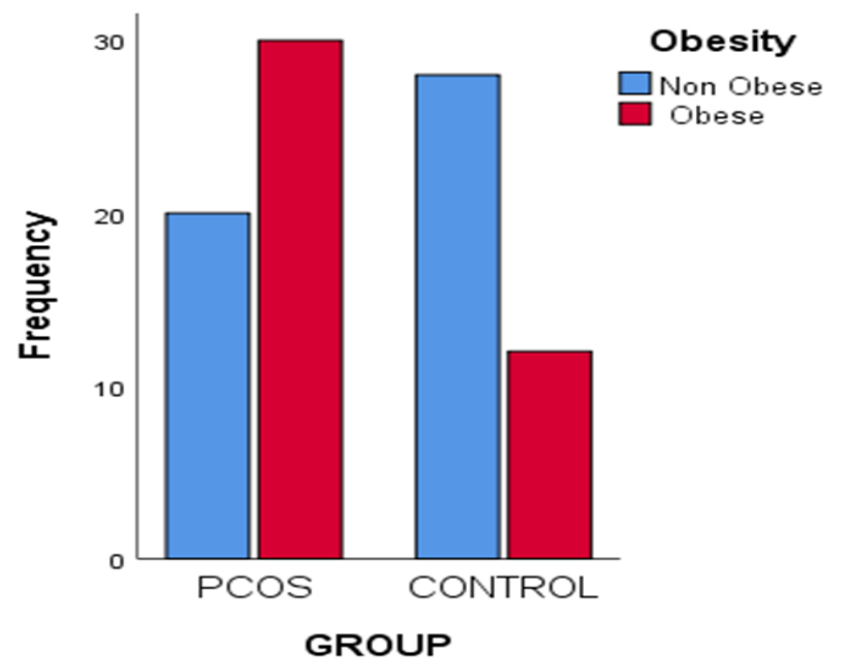

Figure 3. Comparative Analysis of Obesity in PCOS and Control Group

*Difference is statistically significant, $\mathrm{p}<0.05$

Table 3. Risk Analysis of Metabolic Syndrome and its Individual Parameters in PCOS

\begin{tabular}{llll}
\hline Parameter & Odd ratio & $\mathbf{9 5 \%}$ CI & p-value \\
\hline & & & \\
Metabolic Syndrome & 5.211 & $1.086-24.993$ & $\mathbf{0 . 0 3 9 *}$ \\
$\begin{array}{l}\text { Waist circumference } \\
\text { (m) }\end{array}$ & 1.109 & $1.010-1.219$ & $\mathbf{0 . 0 3 0}$ \\
BMI (Kg/m $\left.{ }^{2}\right)$ & 1.093 & $1.003-1.190$ & $\mathbf{0 . 0 4 1 *}$ \\
Waist hip ratio & 12.047 & $2.011-74.57$ & $\mathbf{0 . 0 3 0 *}$ \\
HDL (mg/dl) & 0.954 & $0.919-0.990$ & $\mathbf{0 . 0 1 4 *}$ \\
LDL (mg/dl) & 1.002 & $0.990-1.015$ & 0.695 \\
Triglyceride (mg/dl) & 1.013 & $1.000-1.026$ & 0.054 \\
Glucose (mg/dl) & 1.014 & $0.989-1.040$ & 0.282 \\
Insulin (uU/ml) & 1.009 & $0.986-1.034$ & 0.437 \\
& & & \\
Hypertension (mm Hg) & 1.086 & $0.699-1.688$ & 0.713 \\
& & & \\
\hline
\end{tabular}

*Difference is statistically significant, $\mathrm{p}<0.05$ concentrations were $100 \mathrm{mg} / \mathrm{dl}$ or greater in $22 \%$ of the PCOS study population, respectively.

Figure 3 shows the comparative analysis of obesity in PCOS and control group; obesity was more pronounced in PCOS than controls $(\mathrm{X} 2=8.036, \mathrm{p}=0.005)$. The old ratios of metabolic syndrome and its components are shown in Table 3, with metabolic syndrome, waist circumference, BMI, waist-hip ratio, and HDL, having an odds ratio of $5.211,1.109,1.093,12.047$, and 0.954 , respectively.

\subsection{DISCUSSION}

Polycystic ovary syndrome (PCOS) and Metabolic syndrome (MS) are distinct disorders but related due to observed common features. The $24 \%$ metabolic syndrome prevalence in PCOS reported in this study was lower than the report from some other populations and higher in others. A prevalence of $33.6 \%$ was reported in PCOS women in Brazil [12], while 22.7\% was reported in Iranian women with PCOS [13]. This disparity may be due to variation in individual factors implicated in these conditions in different populations. However, the high prevalence of metabolic syndrome observed in the PCOS compared to the controls suggests the underlying contribution of the various components of metabolic syndrome to the pathophysiology of PCOS in our study population. It is worth highlighting that the commonest features of metabolic syndrome observed in the PCOS participants in this study were markers of obesity and dyslipidemia. This finding is consistent with the role of visceral obesity, dyslipidemia, and insulin resistance in the pathophysiology of PCOS [17].

Patients with PCOS have been reported to have a high prevalence of upper-body obesity, as shown by increased waist circumference and the waist-hip ratio [18]. Obesity results from excess fat accumulation in the body leading to cardiovascular morbidities, insulin resistance, and even the development of type 2 diabetes. An elevated nonesterified fatty acid (NEFA), glycerol, hormones, and pro -inflammatory cytokines, are released from adipose tissues in obese patients [19]. The secretion of cytokines (e.g., leptin, TNF- $\alpha$ ) and an elevated plasma NEFA level produce obesity-induced inflammation that could affect glucose metabolism and insulin sensitivity, resulting in type 2 diabetes [20]. Insulin resistance resulting from obesity could cause elevated fasting blood glucose, the 
major underlying factor in diabetes mellitus. Thus, obesity, defined either by body mass or fat distribution and its associated insulin resistance, is an important risk factor in PCOS.

Furthermore, abdominal fat is more lipolytic than subcutaneous fat, and it also does not respond easily to the antilipolytic action of insulin, thus making intra-abdominal fat more important in causing insulin resistance [21]. Insulin resistance with impairment of $\beta$-cell function leads to the development of diabetes. Insulin resistance in the muscle promotes glucose intolerance, which can be worsened by increased hepatic gluconeogenesis in the insulinresistant liver and diverting excess free fatty acids to the liver. As an alternative energy source to cells during insulin resistance, lipolysis occurs. This provides a high plasma level of NEFA which eventually causes lipotoxicity and a progressive loss of $\beta$-cell function.

Similarly, NEFA also decreases normal insulin release from $\beta$-cell with a marked impairment in glucosestimulated insulin secretion and reduces insulin biosynthesis [19]. Thus, insulin resistance in adipose tissue is associated with decreased glucose uptake and in-creased release of free fatty acids (FFAs), which are converted in the liver to triglyceride-rich very-low-density lipoprotein (VLDL) particles. The delivery of an increased amount of FFAs to the liver and the increased release of FFAs during intrahepatic triglyceride lipolysis seems to regulate glucose production and insulin resistance. In parallel, increased FFA delivery to the liver increases the production of hepatic very-low-density lipoproteins, leading to increased concentration of plasma triglycerides. The latter effect increases the transfer of triglycerides from verylow-density lipoproteins to HDL, leading to an increased HDL clearance and decreased plasma HDL concentration [22]. In other words, FFA homeostasis seems to determine atherogenic dyslipidemia in metabolic syndrome and, consequently, in PCOS. This explains the high prevalence of dyslipidemia observed in our PCOS population in this study.

Elevated plasma small dense low-density lipoprotein (LDL) cholesterol, the most atherogenic subfraction of LDL, has been identified as a key feature in association with elevated triglyceride and low HDL cholesterol in susceptible individuals with greater abdominal fat accumulation (large waist circumference) [23]. The resulting hypertriglyceridemia drives the dyslipidemic triad by promoting the synthesis of small, easily oxidizable dense
LDL and enhanced clearance of HDL, which is believed to be highly atherogenic [10]. The major role of HDL is in reverse cholesterol transport (RCT), in which excess cholesterol is removed from the peripheral vessels and transported back to the liver for disposal [24], and in addition to this function, HDL-cholesterol has a direct action on different cell types which influence cardiovascular and metabolic health. Alteration in the regulation and function of HDL may contribute to increased cardiovascular mortality. Hence, the low HDL associated with metabolic syndrome may predispose PCOS patients to cardiovascular diseases.

Also, in the pathophysiologic spectrum of PCOS, androgen excess possibly acts as a triggering factor in the development of metabolic syndrome, playing a significant role beyond being involved in ovulatory dysfunction. Also, hyperandrogenism tends to amplify the adverse metabolic phenotype of PCOS in a dual-mode, through the aggravation of central adiposity and the perpetuation of insulin resistance [9]. Accumulation of excessive visceral adipose tissue (in the presence or absence of obesity) is associated with insulin resistance, hyperinsulinemia, and glucose intolerance. Insulin resistance typically increases with increasing body fat composition and is an important predisposing mechanism for developing metabolic syndrome. Furthermore, metabolic syndrome is known to be associated with diseases that are leading sources of morbidity and mortality, and such diseases include cardiovascular disorder, Type II diabetes, neurological disease, and nonalcoholic steatohepatitis [25]. Thus, metabolic syndrome comorbidity with PCOS will aggravate the complications resulting from PCOS. The associated metabolic syndrome diseases are usually chronic, causing life-long complications in PCOS that could become lethal.

With the metabolic syndrome driving the twin global epidemics of type 2 diabetes and cardiovascular disease, there is an overwhelming medical and economic imperative to identify risk of developing metabolic syndrome in PCOS individuals, so that early lifestyle interventions and treatment may prevent the development of complications such as diabetes and cardiovascular diseases in POCS.

Metabolic syndrome and its individual components, especially obesity and dyslipidemia, are major risk factors of PCOS in our study population. Routine screening and modulating individual contributors of metabolic syn- 
drome may support or improve PCOS management.

\section{Conflicts of Interest}

The authors declare no competing interests.

\section{Authors' Contributions}

DA collected data, contributed to data analysis and interpretation and manuscript writing. TAS contributed to data analysis and interpretation and made critical assessment of the study. BI contributed to data analysis tools, data analysis and interpretation and critical assessment of the study. OM contributed to study design, data analysis and interpretation and critical assessment of the study. OA conceived and designed the study, contributed to data analysis tools, analysis of data, manuscript writing and assembled the research team and lead proposal design. All authors approved the final copy of the manuscript

\section{References}

1. Conway G., Dewailly D., Diamanti-Kandarakis E., Escobar -Morreale H., Franks S., Gambineri A., et al., ESE PCOS Special Interest Group. The polycystic ovary syndrome: a position statement from the European Society of Endocrinology. Eur. J. Endocrinol. 2014; 171(4): P1-29. doi: 10.1530/EJE-14-0253.

2. Bozdag G, Mumusoglu S, Zengin D, Karabulut E, Yildiz B. The prevalence and phenotypic features of polycystic ovary syndrome: a systematic review and meta-analysis. Hum Reprod. 2016; 31: 2841-2855. doi: 10.1093/humrep/ dew218.

3. Ding T, Hardiman PJ, Peterson I, Wang FF, Qu F, Baio, G. The Prevalence of Polycystic Ovary Syndrome in Reproductive-Aged Women of Different Ethnicity: A Systematic Review and Meta-Analysis. Oncotarget, 2017; 8(56): 96351-96358. doi: 10.18632/oncotarget.19180.

4. Igwegbe AO., Eleje GU., and Enechukwu CI. Polycystic Ovary Syndrome: A Review of Management Outcomes in a Low Resource Setting. Journal of Women's Health, Issues Care, 2013; 2:3. doi:10.4172/2325-9795.1000110

5. NIH Evidence based workshop panel. NIH Evidence based workshop on Polycystic Ovary Syndrome. http:// prevention.nih.gov/workshops/2012/pcos/resources.aspx.

6. European Society of Human Reproduction and Embryology (ESHRE). Revised 2003 consensus on diagnostic criteria and longterm health risks related to polycystic ovary syndrome (PCOS). Human Reproduction. 2004; 19(1): 41-47. https://doi.org/10.1093/humrep/deh098

7. Azziz Ricardo, Enrico Carmina, Didier Dewailly, Evanthia
Diamanti-Kandarakis, Hector F. Escobar-Morreale, Walter Futterweit, Onno E. Janssen, Richard S. Legro, Robert J. Norman, Ann E. Taylor, Selma F. Witchel. The Androgen Excess and PCOS Society criteria for the polycystic ovary syndrome: the complete task force report. Fertility and Sterility. 2009; 91(2):456-88. doi: 10.1016/ j.fertnstert.2008.06.035.

8. International Evidenced-Based Guideline for the Assessment and Management of Polycystic Ovary Syndrome: https://www.monash.edu/__data/assets/ pdf_file/0004/1412644/PCOS_Evidence-BasedGuidelines_20181009.pdf.

9. Kandaraki E, Charikleia C, Evanthia D. Metabolic syndrome and polycystic ovary syndrome... and vice versa. Arq Bras Endocrinol Metab. 2009; 53(2):227-237.https:// doi.org/10.1590/S0004-27302009000200014

10. Halcox J, Quyyumi A. Metabolic Syndrome: Overview and Current Guidelines. Metabolic Syndrome Overview. 2006; pp. $1-12$

11. Cavali ML, Escrivão MA, Brasileiro RS, Taddei JA. Metabolic syndrome: comparison of diagnosis criteria. Jornal de Pediatria (Rio J). 2010; 86(4):325-330. doi:10.2223/ JPED.2006

12. Tavares A, Rêgo Barros R. The Prevalence of Metabolic Syndrome in the Different Phenotypes of Polycystic Ovarian Syndrome. Revista Brasileira de Ginecologia e Obstetrícia / RBGO Gynecology and Obstetrics. 2019; 41(01): 037-043. doi:10.1055/s-0038-1676568

13. Moini A, Fatemeh J, Bita E, Najmeh A. Prevalence of metabolic syndrome in polycystic ovarian syndrome women in a hospital of Tehran. Iranian Journal of Reproductive Medicine. 2012; Vol.10. No. 2. pp: 127-130

14. Lim SS, Norman RJ, Davies MJ, et al. The effect of obesity on polycystic ovary syndrome: a systematic review and metaanalysis. Obes Rev. 2013; 14:95-109. doi: 10.1111/ j.1467-789X.2012.01053.x.

15. Escobar-Morreale HF, San Mill_an JL. Abdominal adiposity and the polycystic ovary syndrome. Trends Endocrinol Metab. 2007; 18(7):266-72. doi: 10.1016/ j.tem.2007.07.003.

16. Grundy SM., Cleeman JI, Daniels SR, et al. "Diagnosis and management of the metabolic syndrome: an American Heart Association/National Heart, Lung, and Blood Institute scientific statement," Circulation, 2005; vol. 112, no. 17, pp. 2735-2752. doi: 10.1161/ CIRCULATIONAHA.105.169404.

17. Joselyn R, Mervin C, Luis O, Milagros R, Jessenia M, José M, María C, Valmore B. "Polycystic Ovary Syndrome, Insulin Resistance, and Obesity: Navigating the Pathophysiologic Labyrinth", International Journal of Reproductive Medicine; Article ID 719050, 17 pages, 2014. https:// 
18 Sam S. Obesity and Polycystic Ovary Syndrome. Obes Manag. 2007; 3(2):69-73. doi:10.1089/obe.2007.0019

19 Mukherjee B, Chowdhury M, Laboni M, Paramita P, Miltu K. Obesity and Insulin Resistance: An Abridged Molecular Correlation. Lipid Insights. 2013; 6: 1-11. doi: 10.4137/LPI.S10805

20 Rabe K, Lehrke M, Parhofer K, Broedl U. Adipokines and insulin resistance. Molecular Medicine. 2008; 14(1112):741-51. doi: 10.2119/2008-00058.Rabe

21 Algoblan A., Alalfi M., Khan M. Mechanism linking diabetes mellitus and obesity. Diabetes, Metabolic Syndrome and Obesity: Targets and Therapy. 2014; 587. doi:10.2147/dmso.s67400

22 Nikolopoulou A, Kadoglou, N. Obesity and metabolic syndrome as related to cardiovascular disease. Expert Review of Cardiovascular Therapy. 2012; 10(7): 933939. doi:10.1586/erc. 12.74

23 Han TS, Lean ME. Metabolic syndrome. Medicine, 2015; 43(2):80-87. doi:10.1016/j.mpmed.2014.11.006.

24 Toth PP. Reverse cholesterol transport: high-density lipoprotein's magnificent mile. Curr Atheroscler Rep. 2003; 5 (5):386-93. DOI:10.1007/s11883-003-0010-5

25 Mendrick DL, Anna MD, Lisa ST, Rodney RD, Yvonne W, Michele AL, Sebastien B, Vijayalaskshmi V, Kenneth LH, Thaddeus TS, Susan GE, Florence GB. Metabolic Syndrome and Associated Diseases: From the Bench to the Clinic. Toxicological Sciences. 2018; 162(1): 36-42. doi: $10.1093 /$ toxsci/kfx233 